\title{
Autologous BPTB ACL Reconstruction Results in Lower Failure Rates Than ACL Repair with and without Synthetic Augmentation at 30 Years of Follow-up
}

\author{
A Prospective Randomized Study
}

Anne N. Sporsheim, MD, Tone Gifstad, MD, PhD, Trond Olav Lundemo, MD, Lars Engebretsen, MD, PhD, Torbjørn Strand, MD, Anders Mølster, MD, PhD, and Jon Olav Drogset, MD, $\mathrm{PhD}$

Investigation performed at the Norwegian University of Science and Technology, Trondheim; the Department of Orthopaedic Surgery, Trondheim University Hospital, Trondheim; the Department of Orthopaedic Surgery, Oslo University Hospital, Oslo; the Department of Orthopaedic Surgery,

Haraldsplass Deacon Hospital, Bergen; and the Department of Orthopaedic Surgery, Haukeland University Hospital, Bergen, Norway

Background: The aim of this study was to compare the 30-year follow-up results after treatment of anterior cruciate ligament $(\mathrm{ACL})$ ruptures with 3 different surgical procedures.

Methods: A total of 150 patients with acute rupture of the ACL who were managed between 1986 and 1988 were randomized into 1 of 3 open repair methods: acute primary repair $(n=49)$, acute repair with a synthetic ligament augmentation device (LAD) $(n=50)$, or reconstruction with an autologous bone-patellar tendon-bone (BPTB) graft with retention of the ACL remnants $(n=51)$. The 30-year follow-up included evaluation of clinical findings, the Tegner and Lysholm questionnaires, radiographic examination, and registration of revisions and knee arthroplasties.

Results: A total of 113 patients (75\%) were available for the follow-up evaluation; 39 patients were in the primary repair group, 39 in the LAD group, and 35 in the BPTB group. Through telephone calls and investigation of patient medical records, 40 of these patients were excluded from further analyses because of revision surgery, knee arthroplasty in the involved or contralateral knee, or ACL reconstruction in the contralateral knee. One patient in the BPTB group had undergone revision $A C L$ reconstruction compared with 12 in the primary repair group $(p=0.002)$ and 9 in the LAD group $(p=0.015)$. Seven patients had undergone knee arthroplasty in the involved knee, with no significant difference among the groups. In the remaining patients, no significant differences were found among the 3 groups with regard to range of motion, laxity, or Tegner and Lysholm scores. Radiographic evidence of osteoarthritis, defined as an Ahlbäck grade of 2 through 5 , was found in $42 \%$ of the operatively treated knees, with no significant differences among the groups.

Conclusions: In the present 30-year follow-up results of a randomized controlled study, the BPTB graft augmented with the remnants of the ruptured ligament provided superior results with regard to the number of revisions compared with both the primary repair and LAD groups. No significant differences were found with respect to range of motion, laxity, activity, function, radiographic evidence of osteoarthritis, and knee arthroplasties.

Level of Evidence: Therapeutic Level I. See Instructions for Authors for a complete description of levels of evidence.

$\mathrm{T}$ he optimal treatment for a ruptured anterior cruciate ligament (ACL) has not been settled. Patients with ACL ruptures are often young and active, and they will live with the results of the surgery for a long time. Acute primary repair was a common surgical procedure in the past ${ }^{1,2}$. Recently, there has been a renewed interest in the method after good outcomes of primary repair of proximal tears were reported ${ }^{3}$. Throughout the years, several different synthetic grafts have

Disclosure: The authors indicated that no external funding was received for any aspect of this work. The Disclosure of Potential Conflicts of Interest forms are provided with the online version of the article (http://links.Iww.com/XXXXXXX). 
The Journal of Bone \& Joint Surgery · Jbjs.org Volume 00-A - Number 00 - September 20, 2019
BPtb aCl Repair Has Lower failure Rates Than Repair with And Without Synthetic Augmentation been introduced for ACL reconstructions ${ }^{4}$. Reconstruction with a synthetic ligament augmentation device (LAD) has shown encouraging short-term results ${ }^{5-7}$; however, long-term studies have described unsatisfactory outcomes ${ }^{8}$. Reconstruction with an autograft is the most accepted method currently. Some studies have provided follow-up data for up to 20 years'; however, very few have followed patients for up to 30 years postoperatively.

The aim of this study was to compare the 30-year followup results for 3 different surgical procedures for a ruptured ACL.

\section{Materials and Methods}

\section{Subjects}

Thical approval for this study was obtained from the E regional ethics committee.

The study included 150 patients who were between 16 and 54 years old (mean, 29 years) and had an acute rupture of the ACL. The inclusion period was from May 1986 to April 1988 in 4 different hospitals. All patients were operatively treated within 10 days after the injury. Patients with posterior cruciate or lateral collateral ligament ruptures were excluded from the study, while patients with concomitant meniscal and/ or medial collateral ligament injuries were included. The meniscal tears were treated with partial arthroscopic resection or open repair. The medial collateral ligament injuries were treated nonoperatively. The patients were randomized with the sealed envelope method into 1 of 3 different surgical procedures; 49 patients were randomized to acute primary repair (the primary repair group); 50 patients, to acute repair with a synthetic LAD (the LAD group); and 51 patients, to an autologous bone-patellar tendon-bone (BPTB) graft augmented with the remnants of the ACL sutured to the graft (the BPTB group). There were no significant differences between the groups with regard to preinjury activity level, age, sex, or additional ligament or meniscal injuries ${ }^{10}$. As previously reported $^{10}$, the patients were evaluated preoperatively and at 6 months as well as $1,2,5$, and 16 years postoperatively ${ }^{11,12}$. The present study describes the results after 30 years.

A total of 128 patients $(85 \%)$ were accounted for at the 30-year follow-up evaluation. After the patients who had died or were cognitively impaired were excluded, 113 patients (75\%) remained for analysis. A total of 40 patients were excluded from clinical and radiographic examination because of a revision of the ACL in the involved knee (22 patients), ACL reconstruction in the contralateral knee (10), knee arthroplasty

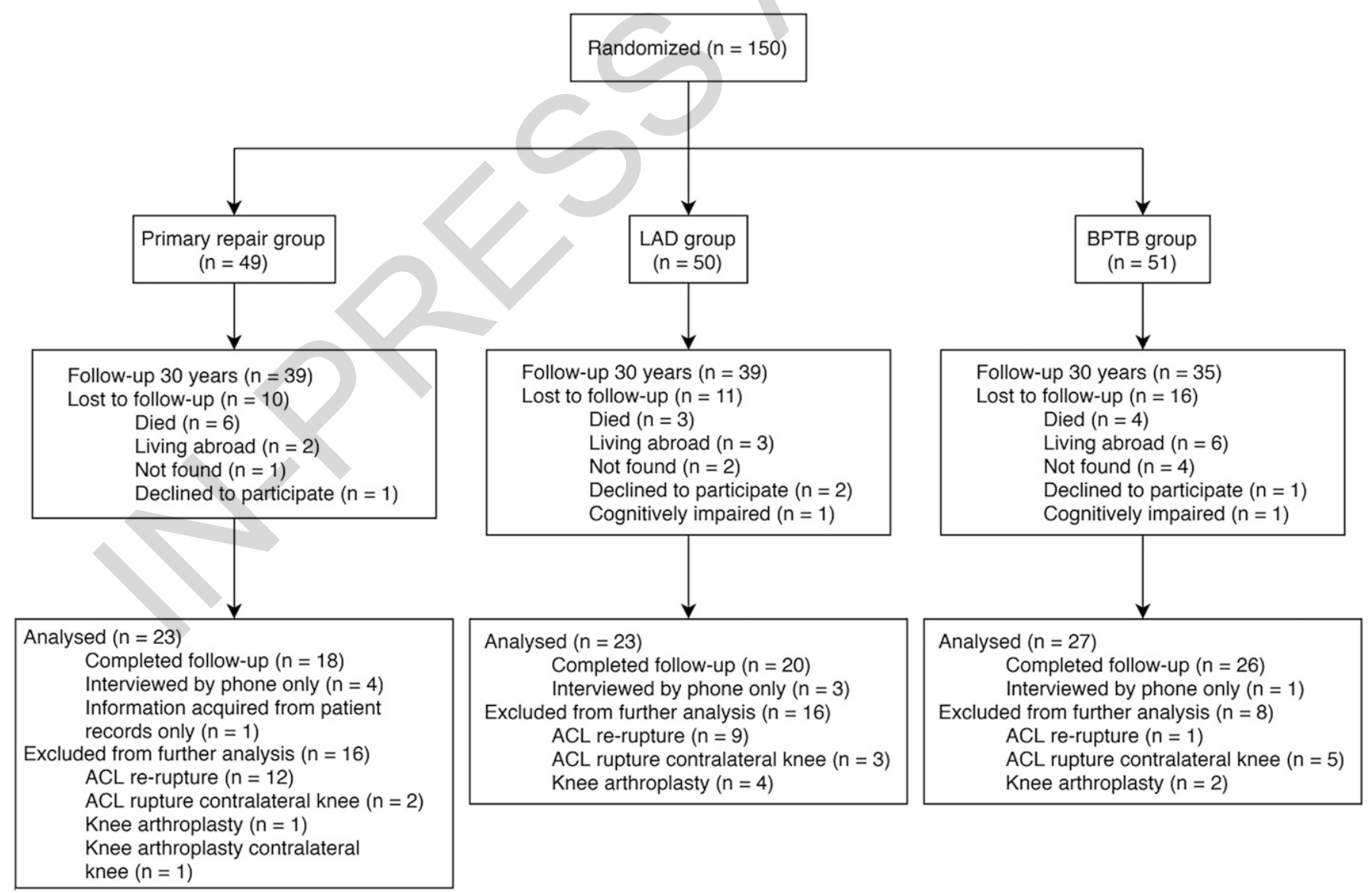

Fig. 1

Flowchart of the patients. 
The Journal of Bone \& Joint Surgery · Jbjs.org Volume 00-A - Number 00 - September 20, 2019

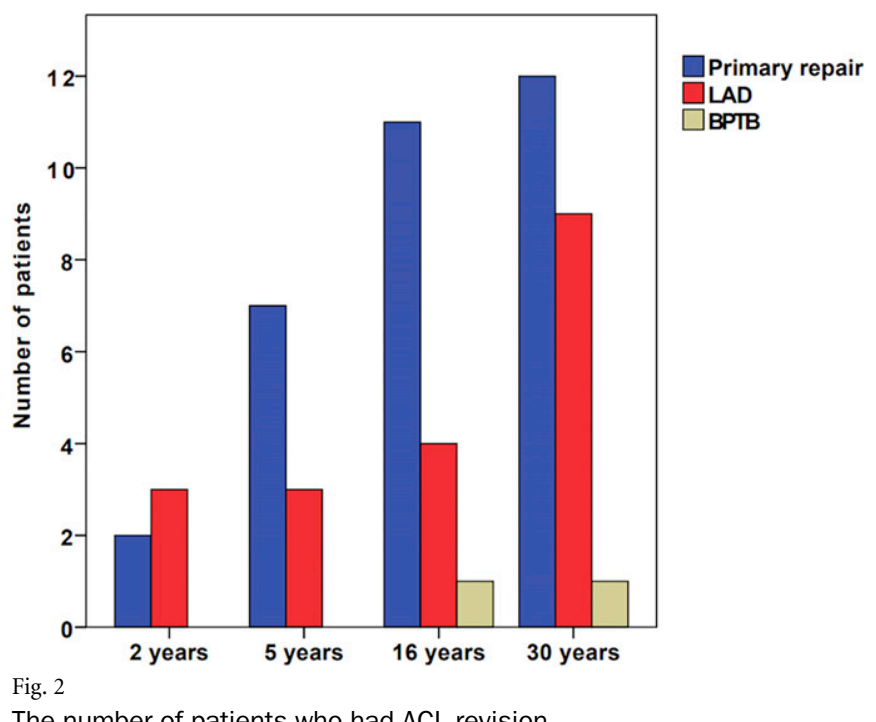

The number of patients who had ACL revision.

in the involved knee (7), and knee arthroplasty in the contralateral knee (1). Patients who had injury and/or surgery of the ACL in the contralateral knee were excluded from the examinations because the Lachman and KT-1000 (MEDmetric) arthrometer results are based on comparisons with the contralateral side. However, if these patients had undergone revision surgery or knee arthroplasty in the involved knee, it was recorded; thus, they were not excluded from these analyses. Sixty-four patients returned for the examinations; they included 18 in the primary repair group, 20 in the LAD group, and 26 in the BPTB group. Additionally, 8 patients were interviewed by telephone. One patient was not available for examination, but all knee records for that patient were available. A flowchart is shown in Figure 1.

\section{Surgical Procedures and Rehabilitation}

The surgical procedures and the rehabilitation for the 3 groups are described in detail in previous publications ${ }^{10-12}$. All repair procedures were performed through a medial arthrotomy. The patients in the primary repair group had primary repair performed according to the method reported by Palmer ${ }^{1}$. In the LAD group, the primary repair was performed with the addition of a braided polypropylene augmentation segment (LAD; 3M). The BPTB group included the patients who had a reconstruction of the ACL with a BPTB graft, in which the ACL remnants were sutured to the graft. After surgery, the patients in all groups were managed with a long leg cast with the knee at $30^{\circ}$ of flexion for 2 weeks and then with a brace for 6 weeks. No weight-bearing was allowed for 8 weeks, and contact sports were not allowed the first year after surgery.

\section{Follow-up}

For comparisons with the former results, the evaluation tools have been the same as those used in the previous follow-up studies. The patients were first approached via a telephone
BPtb aCl Repair Has Lower failure Rates Than Repair with And Without Synthetic Augmentation

call, during which an invitation to return for clinical and radiographic examination was extended. Those having had revision surgery of the ACL, ACL reconstruction in the contralateral knee, or knee arthroplasty were not invited. The first author, together with an experienced orthopaedic surgeon, examined all of the patients. Written informed consent was obtained from all of the examined participants. The physical examination included range of motion and knee laxity evaluated with the pivot-shift test, the Lachman test, and instrumented testing with a KT-1000 arthrometer at $20^{\circ}$ of flexion and with maximum manual force. The level of activity was evaluated with the Tegner score ${ }^{13}$. The knee function was graded according to the Lysholm score ${ }^{13,14}$. Radiographs of both knees were made with the patient standing with the knee at $45^{\circ}$ of flexion and with a $30^{\circ}$ angulation of the beam ${ }^{15}$. The degree of radiographic evidence of osteoarthritis (OA) was graded by an independent radiologist with no clinical knowledge of the patient with the use of the Ahlbäck classification ${ }^{16}$.

Some patients who were unavailable for clinical examination agreed to be interviewed by telephone. The interview included information on additional knee surgery and injuries and the Tegner and Lysholm questionnaires.

The raw data from the previous articles have been available for use in this study as well ${ }^{10-12}$.

\section{Statistical Methods}

The analyses were conducted with SPSS Statistics software (version 24.0; IBM). The Pearson chi-square test and Fisher exact test were used to analyze the significance of associations between the categorical variables. The nonparametric KruskalWallis test and median test were used to compare the outcome measures for the 3 groups at the 30 -year follow-up evaluation. Differences were considered significant when $\mathrm{p}<0.05$.

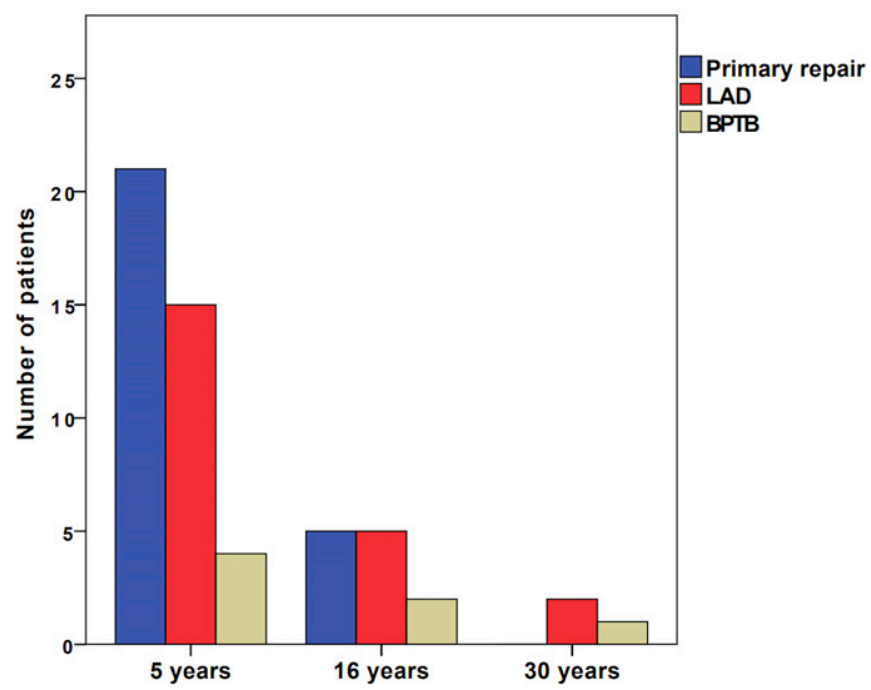

Fig. 3

The number of examined patients with a pivot shift grade of 2 or 3 at the different follow-up intervals. 
The Journal of Bone \& Joint Surgery - JBjS. org Volume 00-A • Number 00 - September 20, 2019

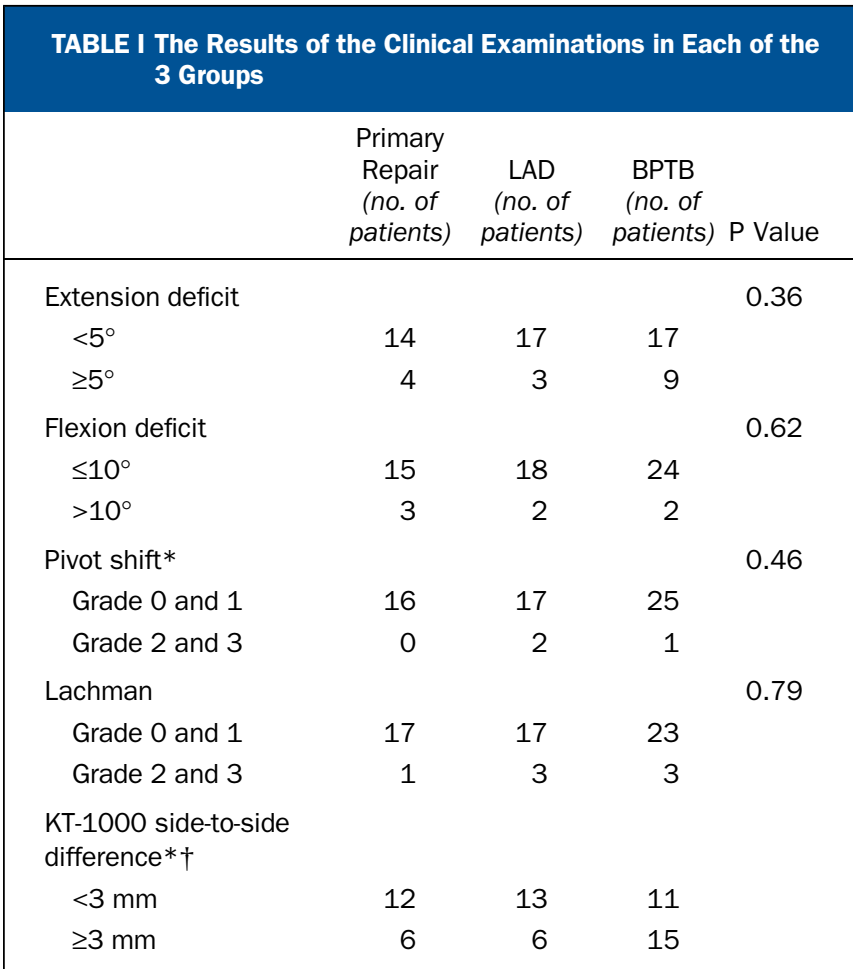

* Data are missing for a few patients because examination results could not be interpreted due to a lack of optimal patient cooperation tThe mean side-to-side difference was $1 \mathrm{~mm}$ (range, -6 to $5 \mathrm{~mm}$ ) in the primary repair group, $1 \mathrm{~mm}$ (range, 4 to $9 \mathrm{~mm}$ ) in the LAD group, and $2 \mathrm{~mm}$ (range, -5 to $8 \mathrm{~mm}$ ) in the BPTB group; the difference was not significant $(p=0.15)$.

\section{Results}

The mean follow-up time in this study was 30 years (range, 29 to 31 years).

The number of revisions in each group from the time of the operation to the 30-year follow-up is shown in Figure 2. The total number of revisions was 22 . The revision rate was $24 \%$ in the primary repair group, $18 \%$ in the LAD group, and $2 \%$ in the BPTB group. The number of revisions was significantly lower in the BPTB group than in both the primary repair group $(\mathrm{p}=0.002)$ and the LAD group $(\mathrm{p}=0.015)$. The revision rate was not significantly different between the primary repair group and the LAD group $(\mathrm{p}=0.61)$.

A subsequent knee arthroplasty was performed in a total of 7 knees, which included 1 in the primary repair group, 4 in the LAD group, and 2 in the BPTB group $(\mathrm{p}=0.39)$. Of the 4 patients in the LAD group, 1 had undergone knee arthroplasty in both knees. All of the knee arthroplasties were performed between the 16-year and the 30-year follow-up.

A total of 64 patients were examined; 28 (44\%) were female and $36(56 \%)$ were male. The mean age at the time of follow-up was 60 years (range, 45 to 84 years). There were no significant differences between the 3 groups with respect to extension deficit $(\mathrm{p}=0.36)$ or flexion deficit $(\mathrm{p}=0.62)$, grade of pivot shift $(\mathrm{p}=0.46)$, Lachman testing $(\mathrm{p}=0.79)$, or KT-
BPtB aCl Repair Has lower failure Rates Than Repair with And Without Synthetic Augmentation

1000 arthrometer measurements $(\mathrm{p}=0.15)$ (Table I). There were also no differences in the median Tegner score $(\mathrm{p}=0.22)$ or the mean Lysholm score $(\mathrm{p}=0.47)$ or with respect to radiographic evidence of $\mathrm{OA}(\mathrm{p}=0.27)$.

Figures 3,4 , and 5 show, respectively, the number of patients at the different follow-up intervals with a pivot shift grade of 2 or 3, the number with a Lachman grade of 2 or 3, and the number with a difference of $\geq 3 \mathrm{~mm}$ in anterior laxity compared with the contralateral side measured with the KT1000 arthrometer.

The median Tegner score at the 30-year follow-up was 3 (range, 1 to 6) for both the primary repair group and the LAD group, while it was 4 (range, 1 to 6 ) for the BPTB group. The median Tegner scores preoperatively and at the different follow-up times are shown in Figure 6.

The mean Lysholm score at 30 years was 76 (95\% confidence interval [CI], 68 to 84 ; range, 42 to 100$)$ for the patients in the primary repair group, 79 ( $95 \% \mathrm{CI}, 71$ to 88 ; range, 23 to $100)$ in the LAD group, and 82 (95\% CI, 75 to 89 ; range, 46 to 100) for the patients in the BPTB group. The mean Lysholm scores at the different follow-up intervals are displayed in Figure 7. At 30 years, good to excellent results (a Lysholm score of $>83$ ) were achieved for $32 \%$ of the patients in the primary repair group, $52 \%$ in the LAD group, and 59\% in the BPTB group.

The radiographic results based on the Ahlbäck classification system are shown in Figures 8-A and 8-B. Radiographic evidence of OA, defined as an Ahlbäck grade of 2 through 5, was found in $42 \%$ of the knees with a reconstructed ACL and in $16 \%$ of the contralateral knees.

\section{Discussion}

The main finding in this 30-year follow-up study was that the number of ACL revisions was significantly higher in

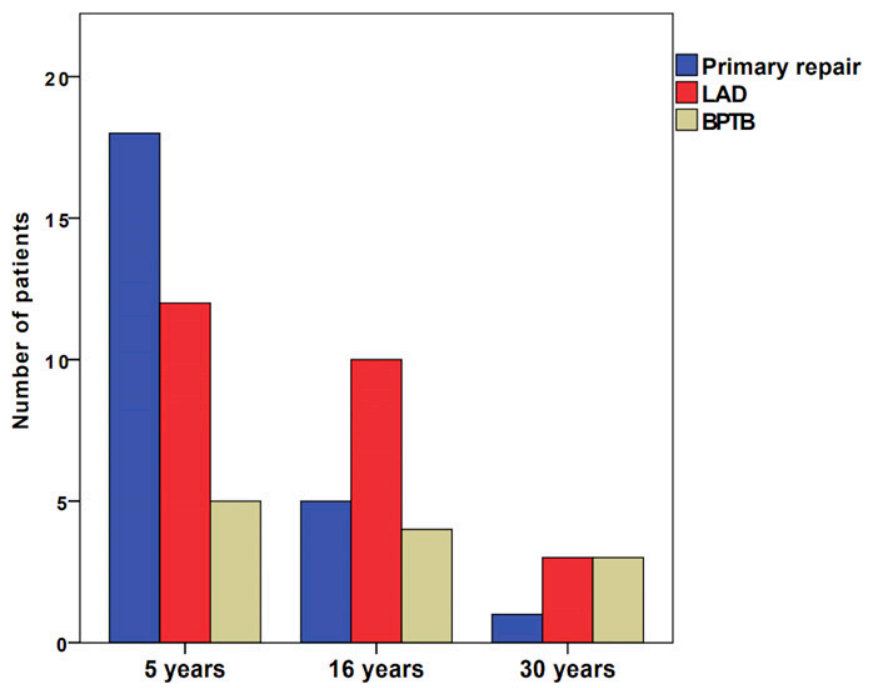

Fig. 4

The number of examined patients with a Lachman grade of 2 or 3 at the different follow-up intervals. 
The Journal of Bone \& Joint Surgery - Jbjs.org Volume 00-A • Number $00 \cdot$ September 20, 2019

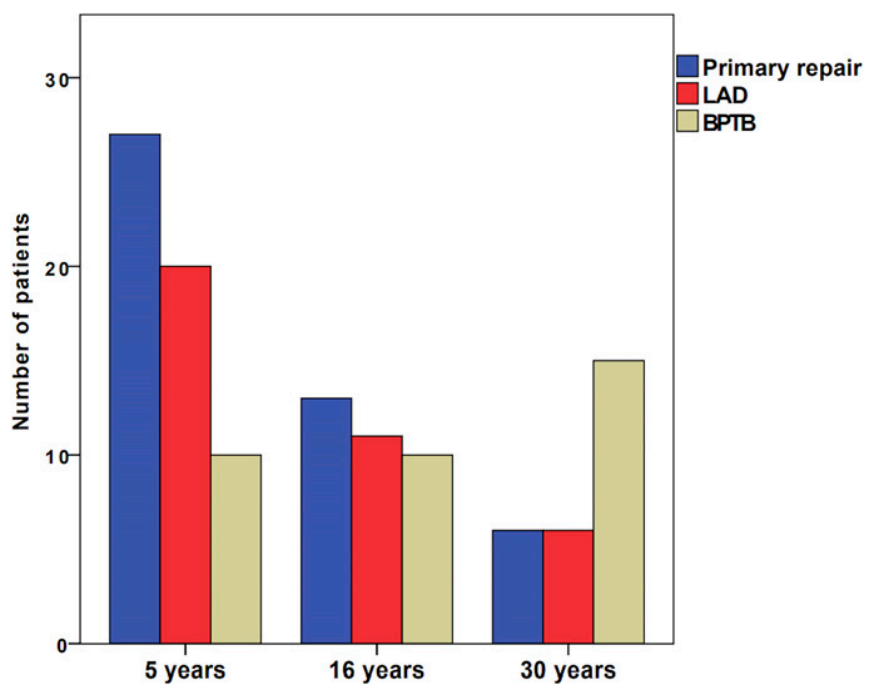

Fig. 5

The number of patients with a side-to-side difference of $\geq 3 \mathrm{~mm}$ measured on the KT-1000 arthrometer at the different follow-up intervals.

the primary repair group and in the LAD group than in the BPTB group. In the remaining patients, no difference was found among the 3 groups with respect to range of motion, laxity, activity, function, radiographic evidence of OA, and number of knee arthroplasties.

A new finding was the significantly higher number of revisions in the LAD group than in the BPTB group, which was in contrast with the results in the previous follow-up studies of these patients $\mathrm{s}^{10-12}$. Other studies have supported the inferiority of the LADs compared with autografts with BPTB or hamstring tendon ${ }^{17-19}$. The reason for the deterioration of the device over time has been assumed to be mechanical and caused by the accumulation of synthetic debris material within the knee ${ }^{18}$.

Primary repair of a ruptured ACL is a procedure that fell out of favor decades ago, partly because of the poor results from the previous follow-up reports of the patients in this study ${ }^{10-12}$ and other studies that showed high rates of persistent symptoms such as pain, swelling, and instability $y^{20-25}$. There has, however, been a resurgence of interest in the procedure in the last few years ${ }^{26,27}$. A systematic review addressed whether primary repair should have a role in the treatment of ruptured ACLs among a highly selected group of patients ${ }^{28}$. That study concluded that a subset of patients achieved acceptable longterm results, but future studies were needed to identify patients who may benefit from this procedure ${ }^{28}$. We found that $32 \%$ of the patients in the primary repair group had good to excellent functional results (a Lysholm score of $>83$ ); however, this was after excluding the patients who had undergone revision surgery or knee arthroplasty. Some studies have suggested that primary repair is a successful treatment alternative for patients with proximal ACL tears and good tissue quality ${ }^{3,27,29,30}$. If the native ACL is preserved, it may benefit the proprioceptive function and biology of the knee ${ }^{29}$. Additionally, the procedure is less invasive and may lead to less morbidity ${ }^{30}$. In our study, the patients were randomized preoperatively, and the primary
BPtb aCl Repair Has Lower failure Rates Than Repair with And without Synthetic Augmentation

repair technique was used on patients with all types of ACL tears.

A noticeable number of patients had developed an increased flexion deficit between the 16-year and the 30-year follow-up. This can be related to older age and/or the development of OA. Compared with the 16-year follow-up results, the 30-year results showed that 15 patients had an increased flexion deficit, while 7 patients had improved flexion ability.

At 30 years, few patients had substantial laxity. Only 3 patients had a pivot shift grade of 2 or 3 , and they included 2 in the LAD group and 1 in the BPTB group. Lachman grade 2 or 3 was demonstrated in 7 patients, including 1 in the primary repair group and 3 each in the LAD and BPTB groups. Most patients who had a positive pivot shift or Lachman test at 5 or 16 years gained a more stable knee over the years. Additional surgery in the 3 groups is not the full explanation for the reduced laxity. Only 4 of the 21 patients in the primary repair group and 5 of the 15 patients in the LAD group who had a pivot shift grade of 2 or 3 at 5 years went on to have revision surgery or knee arthroplasty. A possible reason for the low number of patients with substantial laxity, in addition to fewer examined patients, is the development of OA. The number of patients with a KT-1000 difference of $\geq 3 \mathrm{~mm}$ in anterior laxity was also reduced since the last follow-up; however, the reduction was only in the primary repair group and the LAD group. In the BPTB group, this side-to-side difference of anterior laxity was found in 5 additional patients at 30 years compared with that at 16 years. At the 5 -year and 16-year follow-up reports ${ }^{11,12}$, the knees in the BPTB group showed less laxity than the knees in the other 2 groups evaluated with the pivot shift or Lachman test or the mean anterior laxity as

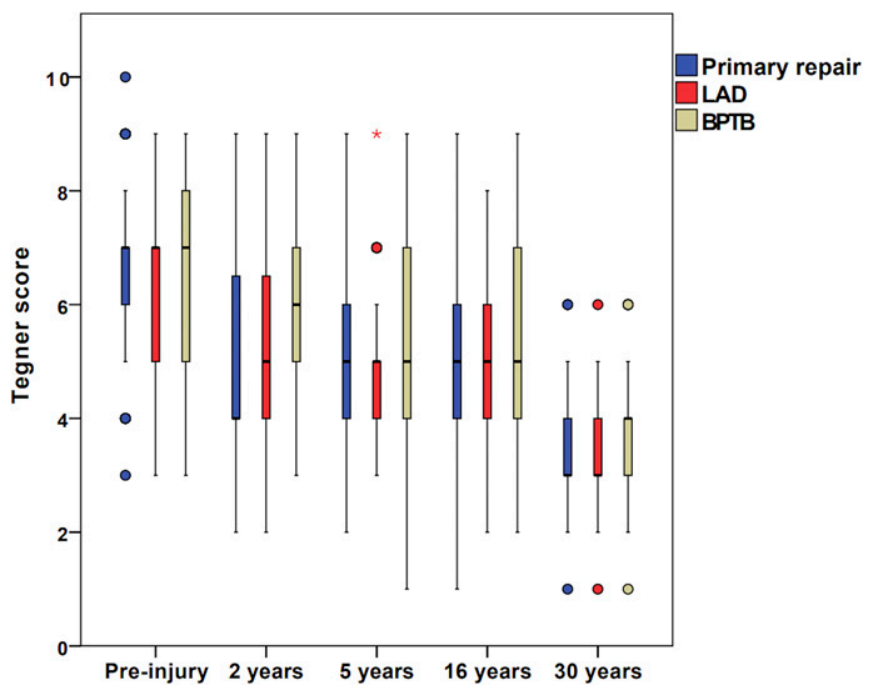

Fig. 6

A box plot showing the median Tegner score at the different follow-up intervals. The top and bottom of each box represent the 25th and 75 th percentiles, the horizontal line within the box is the median, and the I bars are the 10th and 90th percentiles. The circles represent outliers. The asterisk indicates a significant difference. 
The Journal of Bone \& Joint Surgery $\cdot$ JbJS.org Volume 00-A • Number $00 \cdot$ September 20, 2019

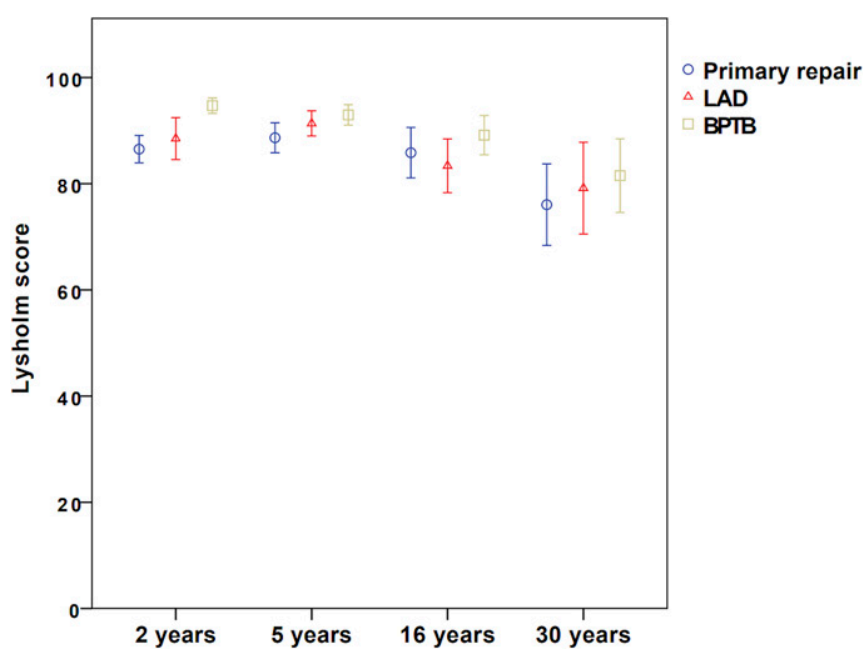

Fig. 7

The mean Lysholm score (and 95\% confidence interval) for each group at the different follow-up intervals.

measured with the KT-1000 arthrometer. No significant differences were found between the 3 groups at 30 years.

The mean age at the 30-year follow-up was 60 years (range, 45 to 84 years), and this is partly a natural explanation for the low Tegner scores in the 3 groups. Older people usually have a lower activity level, which may influence the Lysholm score.

In this study, OA was defined as an Ahlbäck grade of 2 to 5 because grade 0 to 1 is less likely to be symptomatic. On the basis of this definition, radiographic OA was found in $42 \%$ of the operatively treated knees and in $16 \%$ of the uninjured knees. In comparison, the prevalence of OA was said to be $11 \%$ in the knees with an ACL injury at 16 years postoperatively, which was surprisingly low, even though this also included those with an Ahlbäck grade of 1 . The prevalence of OA after ACL surgery has varied substantially in different studies ${ }^{31}$. A
BPtb aCl Repair has lower failure Rates Than Repair with And Without Synthetic Augmentation

systematic review found that the current literature provides no evidence that ACL reconstruction has a prophylactic benefit in reducing the prevalence of OA after ACL injury ${ }^{32}$. In a 14-year follow-up study of knees after ACL reconstruction, the knees treated for an ACL injury with reconstruction had a threefold increased prevalence of OA compared with the contralateral, healthy knee $e^{33}$. In our study, the prevalence of radiographic OA in the operatively treated knees was 2.6 times greater than the prevalence in the uninjured knees. Knee arthroplasty is the final treatment alternative for patients with severe, symptomatic OA. A population-based matched cohort study concluded that patients who had undergone cruciate ligament reconstruction had a cumulative rate of knee arthroplasty after 15 years that was 7 times greater than that in the general population ${ }^{34}$. In a study comparing patients treated nonoperatively after ACL ruptures and individuals without ACL injuries, the risk of needing a knee arthroplasty was found to be 5 times higher in the ACL-injured group $^{35}$. A total of 7 knee arthroplasties were necessary in our study, with no significant differences among the groups.

To our knowledge, the present study is the first randomized controlled trial with a 30-year follow-up of patients after ACL surgery. The study has some limitations. A total of $85 \%$ of the patients were accounted for; however, only $75 \%$ were available for the follow-up evaluation. A relatively high percentage of the patients $(9 \%)$ had died, yet none of the deaths investigated were related to knee problems. Another limitation of the study was that 8 of the patients were only interviewed by telephone. The Ahlbäck classification system for grading OA was used for comparisons with the results of the former followup reports. This was the most used classification system at the time of the original study. However, some problems like poor reliability and reproducibility have been reported using the Ahlbäck classification ${ }^{36,37}$. Another weakness of this study is the use of open surgical procedures, which are no longer commonly performed.
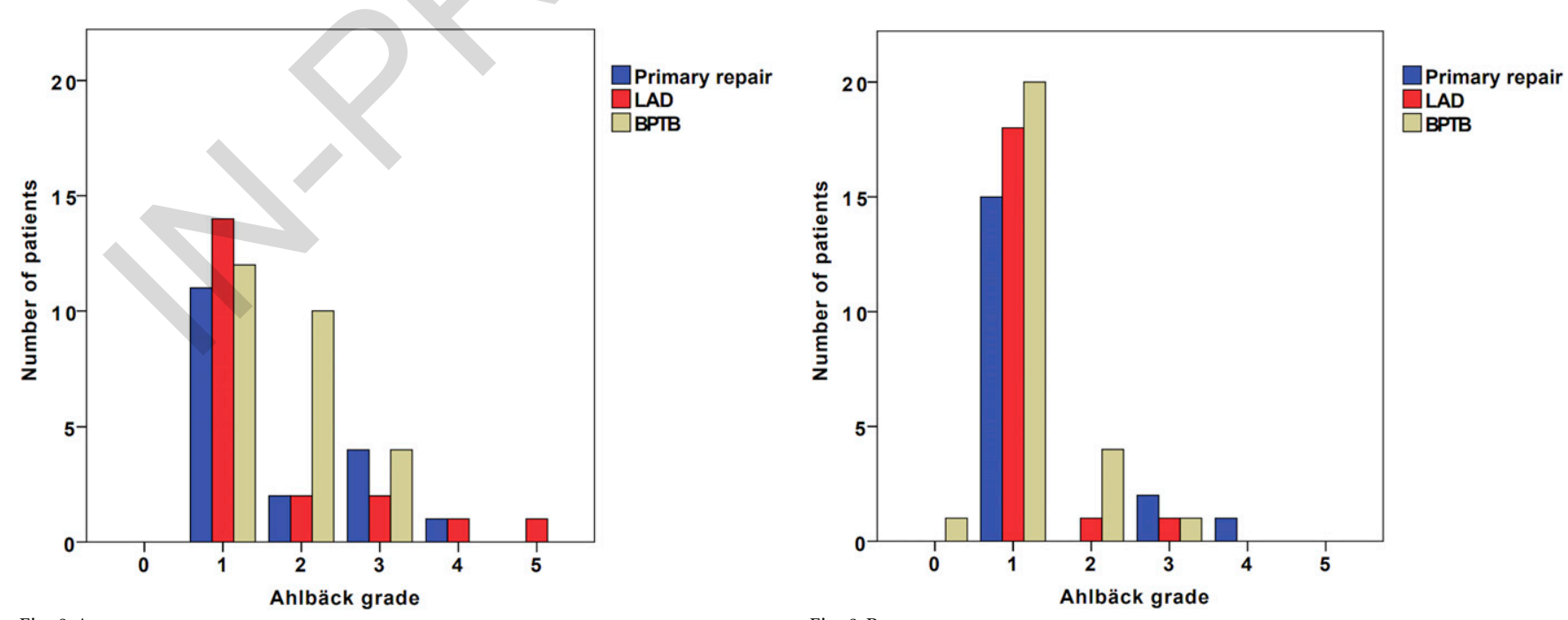

Fig. 8-A

Fig. 8-B

Figs. 8-A and 8-B The number of patients with an Ahlbäck grade of 0 to 5 at the 30-year follow-up evaluation. Fig. 8-A Operatively treated knees.

Fig. 8-B Contralateral knees. 
The Journal of Bone \& Joint Surgery $\cdot$ Jbjs.org Volume 00-A • Number $00 \cdot$ September 20, 2019
BPtb aCl Repair has lower failure Rates Than Repair with and without Synthetic Augmentation

\section{Conclusions}

$\mathrm{T}$ the present 30-year follow-up report of a randomized controlled trial involving surgery on ACL ruptures, reconstruction with BPTB graft with retention of ligament remnants provided superior results with respect to the number of revisions compared with both primary repair and augmentation with an LAD. In the surviving knees, no significant differences among the groups were found with regard to range of motion, laxity, activity, function, $\mathrm{OA}$, and subsequent knee arthroplasties.

NotE: The authors thank Raymond Brønn at Aleris Radiology Center, Trondheim, Norway, for evaluating the radiographs.

Anne N. Sporsheim, $\mathrm{MD}^{1}$

Tone Gifstad, $\mathrm{MD}, \mathrm{PhD}^{2}$

Trond Olav Lundemo, $\mathrm{MD}^{2}$

Lars Engebretsen, $\mathrm{MD}, \mathrm{PhD}^{3,4}$

Torbjørn Strand, $\mathrm{MD}^{5}$

Anders Mølster, $\mathrm{MD}, \mathrm{PhD}^{6,7}$

Jon Olav Drogset, $\mathrm{MD}, \mathrm{PhD}^{1,2}$

${ }^{1}$ Department of Medicine and Health Sciences, Norwegian University of Science and Technology (NTNU), Trondheim, Norway
${ }^{2}$ Department of Orthopaedic Surgery, Trondheim University Hospital, Trondheim, Norway

${ }^{3}$ Department of Orthopaedic Surgery, Oslo University Hospital, Oslo, Norway

${ }^{4}$ Department of Medicine, University of Oslo, Oslo, Norway

${ }^{5}$ Department of Orthopaedic Surgery, Haraldsplass Deacon Hospital, Bergen, Norway

${ }^{6}$ Department of Orthopaedic Surgery, Haukeland University Hospital, Bergen, Norway

${ }^{7}$ University of Bergen, Bergen, Norway

Email address for A.N. Sporsheim: anne.sporsheim@gmail.com Email address for J.O. Drogset: jon.o.drogset@ntnu.no

ORCID iD for A.N. Sporsheim: 0000-0001-8766-5053

ORCID iD for T. Gifstad: 0000-0002-4060-9684

ORCID iD for T.O. Lundemo: 0000-0003-1780-987X

ORCID iD for L. Engebretsen: 0000-0003-2294-921X

ORCID iD for T. Strand: 0000-0001-9586-2786

ORCID iD for A. Mølster: 0000-0002-8068-2851

ORCID iD for J.O. Drogset: 0000-0001-9481-2453

\section{References}

1. Palmer I. On the injuries to the ligaments of the knee joint: a clinical study. 1938. Clin Orthop Relat Res. 2007 Jan;454(454):17-22; discussion 14

2. Nixon JE. Acute injuries of the anterior cruciate ligament of the knee: primary repair. Bull N Y Acad Med. 1980 Jun;56(5):483-7.

3. van der List JP, DiFelice GS. Role of tear location on outcomes of open primary repair of the anterior cruciate ligament: a systematic review of historical studies. Knee. 2017 Oct;24(5):898-908. Epub 2017 Aug 10.

4. Legnani C, Ventura A, Terzaghi C, Borgo E, Albisetti W. Anterior cruciate ligament reconstruction with synthetic grafts. A review of literature. Int Orthop. 2010 Apr; 34(4):465-71. Epub $2010 \mathrm{Feb} 16$.

5. Kennedy JC, Roth JH, Mendenhall HV, Sanford JB. Presidential address. Intraarticular replacement in the anterior cruciate ligament-deficient knee. Am J Sports Med. 1980 Jan-Feb;8(1):1-8.

6. McPherson GK, Mendenhall HV, Gibbons DF, Plenk H, Rottmann W, Sanford JB, Kennedy JC, Roth JH. Experimental mechanical and histologic evaluation of the Kennedy ligament augmentation device. Clin Orthop Relat Res. 1985 Jun;196: 186-95.

7. Roth $\mathrm{JH}$, Kennedy JC, Lockstadt H, McCallum CL, Cunning LA. Polypropylene braid augmented and nonaugmented intraarticular anterior cruciate ligament reconstruction. Am J Sports Med. 1985 Sep-Oct;13(5):321-36.

8. Batty LM, Norsworthy CJ, Lash NJ, Wasiak J, Richmond AK, Feller JA. Synthetic devices for reconstructive surgery of the cruciate ligaments: a systematic review. Arthroscopy. 2015 May;31(5):957-68. Epub 2015 Jan 22.

9. Xie X, Liu X, Chen Z, Yu Y, Peng S, Li Q. A meta-analysis of bone-patellar tendonbone autograft versus four-strand hamstring tendon autograft for anterior cruciate ligament reconstruction. Knee. 2015 Mar;22(2):100-10. Epub 2014 Dec 11.

10. Engebretsen L, Benum P, Fasting $O$, Mølster A, Strand T. A prospective, randomized study of three surgical techniques for treatment of acute ruptures of the anterior cruciate ligament. Am J Sports Med. 1990 Nov-Dec;18(6):585-90.

11. Grøntvedt T, Engebretsen L, Benum $P$, Fasting $O$, Mølster A, Strand T. A prospective, randomized study of three operations for acute rupture of the anterior cruciate ligament. Five-year follow-up of one hundred and thirty-one patients. J Bone Joint Surg Am. 1996 Feb;78(2):159-68.

12. Drogset JO, Grøntvedt T, Robak OR, Mølster A, Viset AT, Engebretsen L. A sixteen-year follow-up of three operative techniques for the treatment of acute ruptures of the anterior cruciate ligament. J Bone Joint Surg Am. 2006 May;88(5): 944-52.

13. Tegner Y, Lysholm J. Rating systems in the evaluation of knee ligament injuries. Clin Orthop Relat Res. 1985 Sep;198:43-9.

14. Lysholm J, Gillquist J. Evaluation of knee ligament surgery results with special emphasis on use of a scoring scale. Am J Sports Med. 1982 May-Jun;10(3):150-4.
15. Rosenberg TD, Paulos LE, Parker RD, Coward DB, Scott SM. The forty-fivedegree posteroanterior flexion weight-bearing radiograph of the knee. J Bone Joint Surg Am. 1988 Dec;70(10):1479-83.

16. Ahlbäck $S$. Osteoarthrosis of the knee. A radiographic investigation. Acta Radiol Diagn (Stockh). 1968;Suppl 277:7-72.

17. Gifstad T, Sole A, Strand T, Uppheim G, Grøntvedt T, Drogset JO. Long-term follow-up of patellar tendon grafts or hamstring tendon grafts in endoscopic ACL reconstructions. Knee Surg Sports Traumatol Arthrosc. 2013 Mar;21(3):576-83. Epub 2012 Mar 10.

18. Olson EJ, Kang JD, Fu FH, Georgescu HI, Mason GC, Evans $\mathrm{CH}$. The biochemical and histological effects of artificial ligament wear particles: in vitro and in vivo studies. Am J Sports Med. 1988 Nov-Dec;16(6):558-70.

19. Savarese A, Lunghi E, Budassi P, Agosti A. Remarks on the complications following $\mathrm{ACL}$ reconstruction using synthetic ligaments. Ital J Orthop Traumatol. 1993;19(1):79-86.

20. Engebretsen $L$, Benum $P$, Sundalsvoll $S$. Primary suture of the anterior cruciate ligament. A 6-year follow-up of 74 cases. Acta Orthop Scand. 1989 Oct;60(5):561-4. 21. Feagin JA Jr, Curl WW. Isolated tear of the anterior cruciate ligament: 5 -year follow-up study. Am J Sports Med. 1976 May-Jun;4(3):95-100.

22. Odensten $\mathrm{M}$, Lysholm J, Gillquist J. Suture of fresh ruptures of the anterior cruciate ligament. A 5-year follow-up. Acta Orthop Scand. 1984 Jun;55(3):

270-2.

23. Strand T, Mølster A, Hordvik M, Krukhaug Y. Long-term follow-up after primary repair of the anterior cruciate ligament: clinical and radiological evaluation 15-23 years postoperatively. Arch Orthop Trauma Surg. 2005 May;125(4):217-21. Epub 2004 Nov 26.

24. Taylor DC, Posner M, Curl WW, Feagin JA. Isolated tears of the anterior cruciate ligament: over 30-year follow-up of patients treated with arthrotomy and primary repair. Am J Sports Med. 2009 Jan;37(1):65-71. Epub 2008 Nov 24.

25. Warren RF. Primary repair of the anterior cruciate ligament. Clin Orthop Relat Res. 1983 Jan-Feb;172:65-70.

26. Perrone GS, Proffen BL, Kiapour AM, Sieker JT, Fleming BC, Murray MM. Benchto-bedside: bridge-enhanced anterior cruciate ligament repair. J Orthop Res. 2017 Dec;35(12):2606-12. Epub 2017 Jul 9.

27. van der List JP, DiFelice GS. Primary repair of the anterior cruciate ligament: a paradigm shift. Surgeon. 2017 Jun;15(3):161-8. Epub 2016 Oct 6.

28. Taylor SA, Khair MM, Roberts TR, DiFelice GS. Primary repair of the anterior cruciate ligament: a systematic review. arthroscopy. 2015 Nov;31(11):2233-47. Epub 2015 Jul 10.

29. DiFelice GS, van der List JP. Arthroscopic primary repair of proximal anterior cruciate ligament tears. Arthrosc Tech. 2016 Sep 19;5(5):e1057-61. 
8

The Journal of Bone \& Joint Surgery $\cdot$ Jbjs. org Volume $00-A \cdot$ Number $00 \cdot$ September 20,2019

30. van der List JP, DiFelice GS. Range of motion and complications following pimary repair versus reconstruction of the anterior cruciate ligament. Knee. 2017 Aug; 24(4):798-807. Epub 2017 May 24.

31. Øiestad BE, Engebretsen L, Storheim K, Risberg MA. Knee osteoarthritis after anterior cruciate ligament injury: a systematic review. Am J Sports Med. 2009 Jul; 37(7):1434-43.

32. Lu B, Gribble PA, Pietrosimone BG. Osteoarthritis prevalence following anterior cruciate ligament reconstruction: a systematic review and numbers-needed-to-treat analysis. J Athl Train. 2014 Nov-Dec;49(6):806-19.

33. Barenius B, Ponzer S, Shalabi A, Bujak R, Norlén L, Ericsson K. Increased risk of osteoarthritis after anterior cruciate ligament reconstruction: a 14-year follow-up study of a randomized controlled trial. Am J Sports Med. 2014 May;42(5):1049-57. Epub 2014 Mar 18.
BPTB ACL Repair Has Lower Failure Rates Than Repair with and Without Synthetic Augmentation

34. Leroux T, Ogilvie-Harris D, Dyer T, Chahal J, Gandhi R, Mahomed N, Weserstein $\mathrm{D}$. The risk of knee arthroplasty following cruciate ligament reconstruction: a population-based matched cohort study. J Bone Joint Surg Am. 2014 Jan 1;96(1): 2-10.

35. Sanders TL, Pareek A, Kremers HM, Bryan AJ, Levy BA, Stuart MJ, Dahm DL, Krych AJ. Long-term follow-up of isolated ACL tears treated without ligament reconstruction. Knee Surg Sports Traumatol Arthrosc. 2017 Feb;25(2):493-500. Epub 2016 May 24.

36. Cali M, De Santis V, Tafuro L. Reliability of the Ahlbäck classification of knee osteoarthritis. Osteoarthritis Cartilage. 2003 Aug;11(8):580-4.

37. Widow J, Cederlund CG, Ranstam J, Kärrholm J. Ahlbäck grading of osteoarthritis of the knee: poor reproducibility and validity based on visual inspection of the joint. Acta Orthop. 2006 Apr;77(2):262-6.

Copyright (C) 2019 by The Journal of Bone and Joint Surgery, Incorporated. Unauthorized reproduction of this article is prohibited. 